\title{
Effects of circadian blood pressure patterns on development of microvascular complications in pediatric patients with type 1 diabetes mellitus
}

\author{
Jeong-Seon Lee, \\ Yun Jeong Lee, \\ Young Ah Lee, \\ Choong Ho Shin
}

Department of Pediatrics, Seoul National University College of Medicine, Seoul, Korea
Purpose: The effects of circadian blood pressure (BP) alterations on the development and progression of microvascular complications in type 1 diabetes mellitus (T1DM) patients are unknown. We evaluated the effects of circadian BP alterations with development of microvascular complications during follow-up with patients with childhood-onset T1DM.

Methods: We investigated the medical records of 81 pediatric patients with T1DM who underwent 24-hour ambulatory BP monitoring (ABPM) between January 2009 and February 2010.

Results: Mean age at diagnosis and ABPM evaluation was $8.0 \pm 3.9$ and $15.6 \pm 2.4$ years, respectively. Hypertension (daytime, nighttime, and 24-hour mean hypertension) data were available in 42 patients. During the 8 years of followup after ABPM, microvascular complications occurred in 8 patients (diabetic retinopathy $[D R]$ alone in 5 , microalbuminuria alone in 2 , and both in 1), of whom 7 had nondipper BP. Nighttime diastolic BP, nighttime mean arterial pressure, and glycated hemoglobin A (HbA1c) level were higher in patients with DR than in those without $\mathrm{DR}(P<0.05$ for all). Daytime or nighttime BP and presence of dipper $\mathrm{BP}$ were not related to microvascular complications, but diabetic microvascular complications were more likely to occur in patients with an older age at diagnosis and higher HbA1c level. The proportion of patients with DR was higher in those with nondipper hypertension (83.3\%) compared with dipper and nondipper normotension ( $0 \%$ and $16.7 \%$, respectively; $P=0.021$ ).

Conclusion: As a predictor of microvascular complications, nondipper hypertension was not significant. Glycemic control rather than nondipper hypertension is the predominant factor determining DR in T1DM patients.

Keywords: Type 1 diabetes mellitus, Blood pressure monitoring, Ambulatory, Hypertension

\section{Highlights}

- In childhood-onset T1DM, glycemic control has the greatest preventive effect on microvascular complications regardless of ABPM abnormalities during 8 years.

- Isolated nocturnal hypertension and blunted nocturnal blood pressure decline are common in T1DM.

\section{Introduction}

In patients with type 1 diabetes mellitus (T1DM), microvascular complications such as microalbuminuria and diabetic retinopathy (DR) are associated with a significant increase in 
long-term mortality. It is important to prevent complications thorough blood sugar management and regular check-ups. Despite the considerable evidence that coexisting hypertension and diabetes increase risk of development and progression of microvascular complications, ${ }^{1)}$ there is insufficient information on the role of blood pressure (BP) alterations in the progression of microvascular complications in diabetes. ${ }^{2)}$ Children with T1DM suffer from both sustained and masked hypertension. ${ }^{3)}$ Some reports found that impaired nighttime BP regulation is associated with microalbuminuria and cardiovascular complications in T1DM. ${ }^{4,5)}$ Furthermore, the 2014 American Heart Association statement recommended routine performance of 24-hour ambulatory BP monitoring (ABPM) in patients with diabetes mellitus for assessing BP patterns such as blunted dipping or isolated sleep hypertension. ${ }^{6)}$

In this study, we investigated factors that affect occurrence of microvascular complications in childhood-onset T1DM patients. We also evaluated effects of circadian BP alterations such as nondipper hypertension on development of microvascular complications during an 8-year follow-up of patients with childhood-onset T1DM.

\section{Materials and methods}

\section{Study population}

We retrospectively investigated the medical records of 91 T1DM pediatric patients who underwent 24-hour ABPM between January 2009 and February 2010 at Seoul National University Children's Hospital (Seoul, Korea). Patients were younger than 19 years of age at evaluation and had participated in a previous ABPM study conducted in our hospital. ${ }^{5)}$ Among them, 10 patients who were confirmed to have microalbuminuria or retinopathy at their ABPM evaluation were excluded. A total of 81 patients ( 33 males and 48 females) with T1DM who were regularly followed for 8 years at Seoul National University Children's Hospital outpatient clinic were included.

\section{Clinical and biochemical assessments}

Laboratory tests included glycated hemoglobin A (HbAlc), lipid profile (total cholesterol, triglycerides, low-density lipoprotein [LDL] cholesterol, high-density lipoprotein [HDL] cholesterol), 24-hour urine microalbumin excretion, albuminto-creatinine ratio, free thyroxine, thyroid-stimulating hormone, and triiodothyronine. Data on T1DM duration, height, weight, and age at diagnosis were collected. Mean $\mathrm{HbA1c}$ level over the total T1DM duration was recorded from patient files. Blood samples were obtained by venipuncture the morning after an 8to 12-hour fast. Levels of HbAlc, lipids, free thyroxine, thyroidstimulating hormone, and triiodothyronine were measured. Some patients could not fast for 12 hours because of risk of hypoglycemia. Total cholesterol, LDL cholesterol, and HDL cholesterol levels were measured by enzymatic calorimetry. The albumin-to-creatinine ratio $(\mu \mathrm{g} / \mathrm{mg})$ or 24 -hour urine microalbumin excretion $(\mathrm{mg} / 24 \mathrm{hr})$ was measured in a random urine or 24-hour urine sample collected from each subject, respectively, using turbidimetric immunoassay. Height $(\mathrm{cm})$ was measured using the Harpenden stadiometer (Holtain Ltd., Crymych, Wales, UK), and weight ( $\mathrm{kg}$ ) was measured using a digital scale (150 A; Cas Co. Ltd., Seoul, Korea). Body mass index (BMI) was calculated as weight (kg) divided by height squared $\left(\mathrm{m}^{2}\right)$. The standard deviation score (SDS) for height, weight, and BMI was assigned based on the 2017 Korean National Growth Charts for patients over 2 years old. ${ }^{7}$

\section{Definition of microvascular complications}

Microvascular complications were evaluated over approximately 8 years of follow-up after ABPM assessment. Screening for DR presence or absence was performed by trained ophthalmologists using direct fundoscopy with mydriasis. Age at first pathological eye examination was defined as age at DR onset. Microalbuminuria was defined as excretion of $30-300 \mathrm{mg}$ of albumin per 24 hours or a spot urine albumin-tocreatinine ratio of $30-300 \mu \mathrm{g} / \mathrm{mg}$ on 2 of 3 urine collections.

\section{BP measurements}

Clinic BP was defined as the average of 2 sphygmomanometer measurements conducted with the patient in a sitting position for at least 5 minutes. ABPM was performed using the Tonoport V ambulatory BP system (General Electric, Milwaukee, WI, USA), with a suitably sized cuff placed around each patient's nondominant arm. The BP system was programmed to measure BP every 20 minutes from 8:00 AM to 10:00 PM and every 30 minutes from 10:00 PM to 8:00 AM. Self-reported sleepwake times have been used to classify ABPM data into daytime and nighttime periods. The BP indices were calculated from 24 hours, daytime, and nighttime measurements. ${ }^{5}$ Systolic and diastolic BPs and mean arterial BP (MAP) were analyzed according to normal values adjusted for sex and height, and their SDS were calculated. ${ }^{8)}$ The nighttime dip in BP was calculated using the following formula: systolic or diastolic nighttime dip $=($ daytime systolic or diastolic mean BP - nighttime systolic or diastolic mean BP)/daytime systolic or diastolic mean BP. ${ }^{5)}$ Hypertension was defined as daytime, nighttime, or 24-hour mean systolic or diastolic BP higher than the 95th percentile of the normal pediatric ABPM value, which was adjusted for sex and height. ${ }^{8)}$ Normal BP was defined as daytime, nighttime, and 24-hour systolic and diastolic BP $<95$ th percentile for age and sex. Nondipper status was defined as nighttime systolic $\mathrm{BP}$ or diastolic BP $<10 \%$ of the diurnal mean value. Patients were categorized into 3 circadian BP groups: dipper, nondipper normotension, and nondipper hypertension. 


\section{Statistical analysis}

All continuous variables were tested for normality and are presented as mean \pm standard deviation or median with interquartile range. Student $t$-test or the Mann-Whitney $U$-test was used to compare continuous variables, and the chisquare test or Fisher exact test was used to compare categorical variables between the 2 groups. The Cox proportional hazards model was used to identify predictors of microvascular complications 8 years after ABPM evaluation. Event-free survival curves for total microvascular complications, DR, and microalbuminuria were constructed using the Kaplan-Meier method. Multivariate models were adjusted for age at T1DM diagnosis and mean $\mathrm{HbAlc}$ level from diagnosis to last followup. $P<0.05$ was considered statistically significant. Statistical analyses were performed using IBM SPSS Statistics ver. 22.0 (IBM Co., Armonk, NY, USA).

\section{Results}

\section{Characteristics of the study population}

The clinical characteristics of patients with T1DM are presented in Table 1. Mean patient age was $15.6 \pm 2.4$ years, mean
T1DM duration was $7.5 \pm 4.0$ years, mean BMI was $-0.04 \pm 0.86$ (SDS), and mean HbAlc level was $8.9 \% \pm 1.9 \%$ at the time of ABPM evaluation. Among the 81 patients, 33 were male, and 25 were in puberty. No patient had both microalbuminuria and DR between January 2009 and February 2010.

\section{BP profiles}

All BP values (SDS) were elevated (Table 2), especially nighttime systolic BP $(1.03 \pm 1.26)$, diastolic BP $(1.33 \pm 1.04)$, and MAP $(1.33 \pm 1.23)$. All BP profiles $(\mathrm{mmHg})$ are summarized in Supplementary Table 1. Hypertension (daytime, nighttime, and 24-hour mean hypertension) was observed in 42 patients (51.9\%): daytime hypertension in 18 patients (23.5\%), nighttime hypertension in 35 patients (43.2\%), and 24-hour hypertension in 20 patients (24.7\%). Fifty-one patients (62.9\%) had nondipper BP. Using the results of 24-hour ABPM, patients were categorized into 3 circadian BP groups: dipper $(n=30,37.0 \%)$, nondipper normotension $(\mathrm{n}=18,22.2 \%)$, and nondipper hypertension $(\mathrm{n}=33,40.7 \%)$. There were no significant differences among the 3 groups in age at diagnosis, T1DM duration, sex ratio, puberty status, or mean HbAlc level from T1DM diagnosis to ABPM evaluation.

Thirteen of 81 patients had their office BP readings

Table 1. Baseline characteristics of the participants

\begin{tabular}{|c|c|c|c|c|c|c|c|}
\hline \multirow{2}{*}{ Parameter } & \multirow{2}{*}{ Total $(n=81)$} & \multicolumn{2}{|c|}{ Diabetic retinopathy } & \multirow{2}{*}{$P$-value } & \multicolumn{2}{|c|}{ Microalbuminuria } & \multirow{2}{*}{$P$-value } \\
\hline & & No $(n=75)$ & Yes $(n=6)$ & & No $(n=78)$ & Yes $(n=3)$ & \\
\hline Male sex & $33(40.7)$ & $45(60.0)$ & $3(50.0)$ & 0.634 & $33(42.3)$ & $0(0)$ & 0.146 \\
\hline Age at diagnosis (yr) & $8.0 \pm 3.9$ & $8.0 \pm 4.0$ & $7.9 \pm 2.1$ & 0.958 & $7.9 \pm 3.9$ & $9.9 \pm 1.9$ & 0.407 \\
\hline Puberty at diagnosis & $25(30.9)$ & $23(30.7)$ & $2(33.3)$ & 0.892 & $23(29.5)$ & $2(66.7)$ & 0.174 \\
\hline \multicolumn{8}{|c|}{ At the time of ABPM evaluation } \\
\hline Age (yr) & $15.6 \pm 2.4$ & $15.5 \pm 2.5$ & $16.5 \pm 2.0$ & 0.337 & $15.5 \pm 2.5$ & $16.3 \pm 2.1$ & 0.617 \\
\hline T1DM duration (yr) & $7.5 \pm 4.0$ & $7.5 \pm 4.1$ & $8.6 \pm 2.9$ & 0.529 & $7.6 \pm 4.1$ & $6.4 \pm 3.8$ & 0.619 \\
\hline $\mathrm{BMI}\left(\mathrm{kg} / \mathrm{m}^{2}, \mathrm{sDS}\right)$ & $-0.0 \pm 0.9$ & $-0.0 \pm 0.9$ & $-0.1 \pm 0.6$ & 0.787 & $-0.1 \pm 0.9$ & $0.9 \pm 0.7$ & 0.066 \\
\hline Mean $\mathrm{HbA1c}(\%)^{*}$ & $8.9 \pm 0.3$ & $8.8 \pm 0.2$ & $10.5 \pm 0.7$ & 0.009 & $8.8 \pm 1.3$ & $12.2 \pm 3.2$ & 0.204 \\
\hline
\end{tabular}

Values are presented as number (\%) or mean \pm standard deviation.

SDS, standard deviation score; BMI, body mass index; HbA1c, glycated hemoglobin A; ABPM, ambulatory blood pressure monitoring.

"Mean $\mathrm{HbA} 1 \mathrm{c}$ from diagnosis to ABPM evaluation.

Table 2. Blood pressure profiles (SDS) of the T1DM patients

\begin{tabular}{|c|c|c|c|c|c|c|c|}
\hline \multirow{2}{*}{ Parameter } & \multirow{2}{*}{ Total $(n=81)$} & \multicolumn{2}{|c|}{ Diabetic retinopathy } & \multirow{2}{*}{$P$-value } & \multicolumn{2}{|c|}{ Microalbuminuria } & \multirow{2}{*}{$P$-value } \\
\hline & & No $(n=75)$ & Yes $(n=6)$ & & No $(n=78)$ & Yes $(n=3)$ & \\
\hline 24-Hour systolic blood pressure & $0.63 \pm 1.29$ & $0.59 \pm 1.30$ & $1.07 \pm 1.13$ & 0.362 & $0.63 \pm 1.31$ & $0.53 \pm 0.92$ & 0.875 \\
\hline 24-Hour diastolic blood pressure & $0.92 \pm 1.13$ & $0.91 \pm 1.15$ & $1.12 \pm 0.83$ & 0.582 & $0.90 \pm 1.14$ & $1.51 \pm 0.72$ & 0.273 \\
\hline 24-Hour mean arterial pressure & $0.87 \pm 1.28$ & $0.83 \pm 1.30$ & $1.35 \pm 1.06$ & 0.297 & $0.85 \pm 1.30$ & $1.36 \pm 0.89$ & 0.424 \\
\hline Daytime systolic blood pressure & $0.40 \pm 1.24$ & $0.38 \pm 1.24$ & $0.65 \pm 1.24$ & 0.625 & $0.40 \pm 1.25$ & $0.24 \pm 0.74$ & 0.752 \\
\hline Daytime diastolic blood pressure & $0.61 \pm 1.15$ & $0.62 \pm 1.17$ & $0.57 \pm 0.97$ & 0.906 & $0.60 \pm 1.16$ & $0.98 \pm 0.53$ & 0.342 \\
\hline Daytime mean arterial pressure & $0.75 \pm 0.13$ & $0.75 \pm 1.16$ & $0.81 \pm 1.14$ & 0.905 & $0.75 \pm 1.17$ & $0.91 \pm 0.64$ & 0.704 \\
\hline Nighttime systolic blood pressure & $1.03 \pm 1.26$ & $0.98 \pm 1.27$ & $1.75 \pm 0.81$ & 0.071 & $1.04 \pm 1.26$ & $0.88 \pm 1.22$ & 0.845 \\
\hline Nighttime diastolic blood pressure & $1.33 \pm 1.04$ & $1.29 \pm 1.06$ & $1.85 \pm 0.46$ & 0.031 & $1.32 \pm 1.05$ & $1.74 \pm 0.56$ & 0.321 \\
\hline Nighttime mean arterial pressure & $1.33 \pm 0.14$ & $1.28 \pm 1.26$ & $1.98 \pm 0.57$ & 0.031 & $1.32 \pm 1.25$ & $1.50 \pm 0.92$ & 0.774 \\
\hline
\end{tabular}

Values are presented as mean \pm standard deviation (SDS).

SDS, standard deviation score; T1DM, type 1 diabetes mellitus. 
Table 3. Characteristics of 8-year follow-up in T1DM patients

\begin{tabular}{|c|c|c|c|c|c|c|c|}
\hline \multirow{2}{*}{ Parameter } & \multirow{2}{*}{ Total $(n=81)$} & \multicolumn{2}{|c|}{ Diabetic retinopathy } & \multirow{2}{*}{$P$-value } & \multicolumn{2}{|c|}{ Microalbuminuria } & \multirow{2}{*}{$P$-value } \\
\hline & & No $(n=75)$ & Yes $(n=6)$ & & No $(n=78)$ & Yes $(n=3)$ & \\
\hline Age (yr) & $23.3 \pm 2.6$ & $24.4 \pm 2.8$ & $23.2 \pm 2.6$ & 0.111 & $25.3 \pm 3.0$ & $23.6 \pm 2.3$ & 0.169 \\
\hline T1DM duration (yr) & $15.2 \pm 4.2$ & $16.4 \pm 4.3$ & $14.9 \pm 2.9$ & 0.313 & $17.4 \pm 4.5$ & $13.9 \pm 2.8$ & 0.100 \\
\hline $\mathrm{BMI}\left(\mathrm{kg} / \mathrm{m}^{2}\right)$ & $20.5 \pm 0.3$ & $22.5 \pm 2.9$ & $20.0 \pm 1.1$ & 0.001 & $22.4 \pm 2.9$ & $21.9 \pm 3.4$ & 0.765 \\
\hline Mean $\mathrm{HbA} 1 \mathrm{c}(\%)$ & $8.6 \pm 1.1$ & $8.5 \pm 1.0$ & $10.1 \pm 0.7$ & $<0.001$ & $8.6 \pm 1.1$ & $10.1 \pm 0.6$ & 0.019 \\
\hline Follow-up duration $(y r)^{\dagger}$ & $7.7 \pm 0.8$ & $8.9 \pm 1.8$ & $6.1 \pm 1.1$ & $<0.001$ & $8.0 \pm 0.1$ & $6.6 \pm 0.9$ & 0.118 \\
\hline Age at event $(y r)^{\ddagger}$ & & NA & $22.6 \pm 2.2$ & & NA & $22.9 \pm 2.6$ & \\
\hline T1DM duration at event (yr) $)^{\ddagger}$ & & NA & $14.6 \pm 2.6$ & & NA & $13.0 \pm 4.4$ & \\
\hline Blood pressure group & & & & 0.021 & & & 0.774 \\
\hline Dipper & $30(37.0)$ & $30(40.0)$ & $0(0)$ & & $29(37.1)$ & $1(33.3)$ & \\
\hline Nondipper normotension & $18(22.2)$ & $17(22.7)$ & $1(16.7)$ & & $17(21.8)$ & $1(33.3)$ & \\
\hline Nondipper hypertension & $33(40.7)$ & $28(37.3)$ & $5(83.3)$ & & $32(41.0)$ & $1(33.3)$ & \\
\hline
\end{tabular}

Values are presented as mean \pm standard deviation or number (\%).

T1DM, type 1 diabetes mellitus; BMI, body mass index; HbA1c, glycated hemoglobin A; NA, not available.

${ }^{\dagger}$ From ambulatory blood pressure monitoring evaluation to last follow-up about 8 years; ${ }^{\ddagger}$ Event means development of microvascular complications.
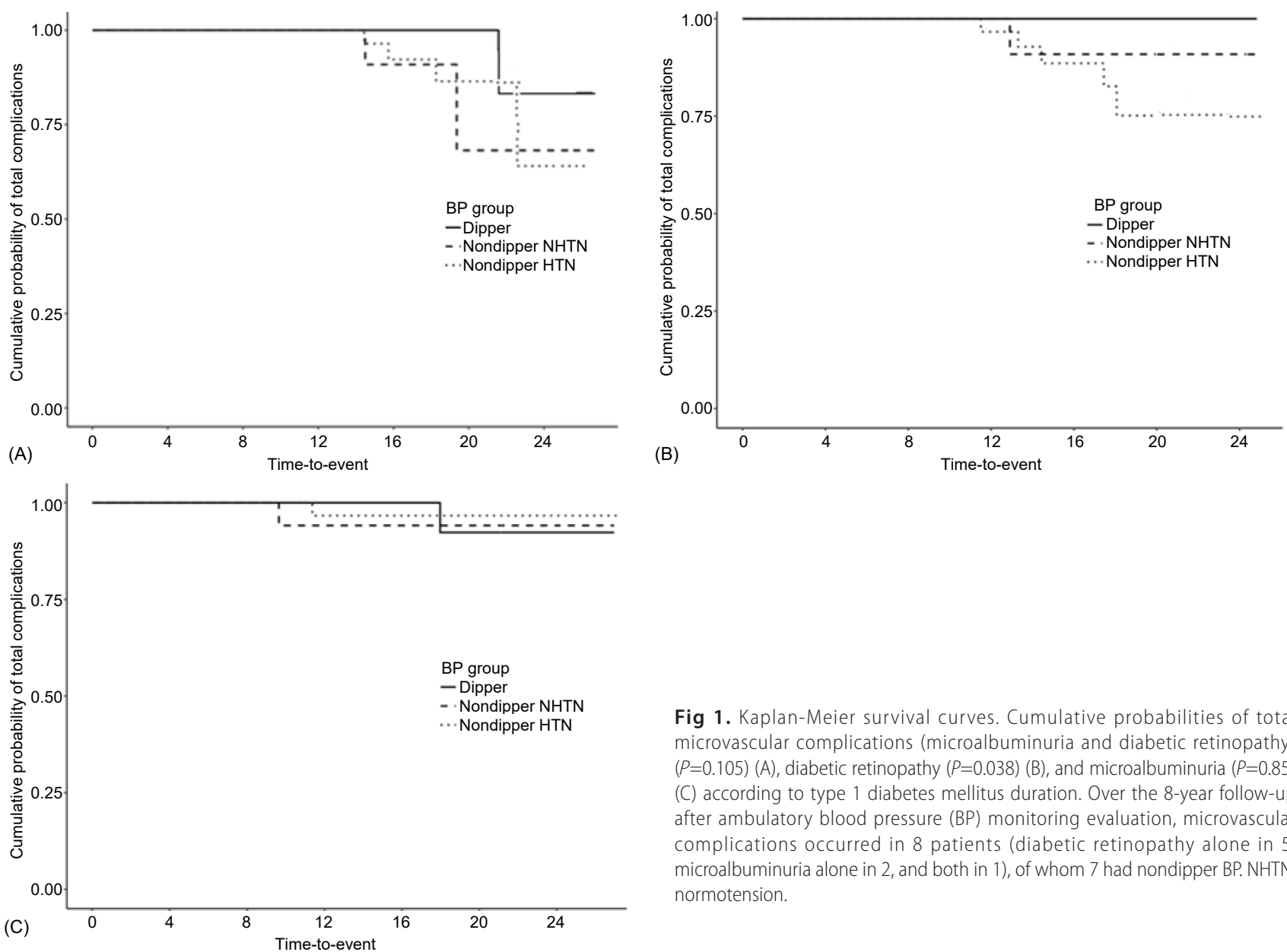

Fig 1. Kaplan-Meier survival curves. Cumulative probabilities of total microvascular complications (microalbuminuria and diabetic retinopathy) $(P=0.105)(A)$, diabetic retinopathy $(P=0.038)(B)$, and microalbuminuria $(P=0.85)$ (C) according to type 1 diabetes mellitus duration. Over the 8-year follow-up after ambulatory blood pressure (BP) monitoring evaluation, microvascular complications occurred in 8 patients (diabetic retinopathy alone in 5, microalbuminuria alone in 2, and both in 1), of whom 7 had nondipper BP. NHTN, normotension.

corresponding with hypertension. When ABPM was measured, 5 patients had high BP only during daytime, and 8 patients had hypertension in the 24-hour mean measurement, daytime, and nighttime; i.e., there was no evidence of white-coat hypertension.

Among 68 patients with normal office BP, 34 patients had any ABPM hypertension (24-hour mean, daytime, or nighttime hypertension); i.e., 34 patients had masked hypertension. Their distribution is expressed in a Venn diagram (Supplementary 
Fig. 1). Since office BP was measured during the day, we compared office BP and daytime ABPM using paired $t$-tests (Supplementary Table 2). Office BP was significantly lower than daytime ABPM, apparently reflecting the characteristics of the patient group that had masked hypertension (38 of 81,46.9\%).

\section{Measurements at the 8-year follow-up point}

Mean age at follow-up was $23.3 \pm 2.6$ years, mean T1DM duration was $15.2 \pm 4.2$ years, BMI was $22.4 \pm 2.9 \mathrm{~kg} / \mathrm{m}^{2}$, and mean $\mathrm{HbAlc}$ level was $8.6 \% \pm 1.1 \%$ (Table 3 ). Over the 8 -year follow-up after ABPM evaluation, microvascular complications occurred in 8 patients (DR alone in 5, microalbuminuria alone in 2 , and both in 1; Fig. 1), 7 of whom had nondipper BP. Mean $\mathrm{HbAlc} \mathrm{level} \mathrm{(from} \mathrm{diagnosis} \mathrm{to} \mathrm{last} \mathrm{follow-up)} \mathrm{was} \mathrm{significantly}$ lower in the non-DR group than DR group $(8.5 \% \pm 1.0 \%$ vs. $10.1 \% \pm 0.7 \% ; P<0.001$ ) (Table 3 ). Mean clinic systolic BP, nighttime diastolic BP, and MAP were significantly higher in the DR than non-DR group $(P=0.049, P=0.033$, and $P=0.017$, respectively; Table 2 , Supplementary Table 1 ). Although not statistically significant, the other BP profiles (clinic diastolic BP and MAP; 24-hour systolic BP, diastolic BP, and MAP; daytime systolic BP, diastolic BP, and MAP; and nighttime systolic BP, diastolic BP, and MAP) were also higher in the DR group (Table 2). The proportion of patients with DR was significantly higher in the nondipper hypertension group (83.3\%) compared with the dipper and nondipper normotension groups ( $0 \%$ and $16.7 \%$, respectively; $P=0.021$ ). Univariate Cox regression analysis after adjustment for T1DM duration showed that mean $\mathrm{HbAlc}$ level (hazard ratio [HR], 4.84; 95\% confidence interval $[\mathrm{CI}], 1.97-11.92 ; P<0.001)$, age at diagnosis (HR, 1.33; 95\% CI, $0.98-1.81 ; P=0.07)$, and puberty status at diagnosis (HR, 8.478; 95\% CI, 1.095-65.666; $P=0.041$ ) were significantly related to development of microvascular complications (Table 4); none of the BP profiles showed a significant relationship. In a multivariate analysis adjusted for age at diagnosis and mean $\mathrm{HbAlc}$ level, neither the BP profile nor presence of dipper BP was related to development of microvascular complications. Mean $\mathrm{HbAlc}$ level (from diagnosis to last follow-up) was significantly higher in the microalbuminuria than nonmicroalbuminuria group $(10.1 \% \pm 0.6 \%$ vs. $8.6 \% \pm 1.1 \%$; $P=0.019$ ) (Table 3 ). Unlike DR, BP profiles were not significantly related to microalbuminuria (Table 2, Supplementary Table 1). In a univariate Cox regression analysis adjusted for T1DM duration, mean HbAlc level (HR, 3.78; 95\% CI, 1.19-12.03; $P=0.024$ ) and age at diagnosis ( $\mathrm{HR}, 1.54 ; 95 \% \mathrm{CI}, 0.93-2.55$; $P=0.096$ ), but not puberty status at diagnosis or BP profiles, were significantly related to development of microvascular complications (Table 4). In a multivariate analysis adjusted for age at diagnosis and mean $\mathrm{HbAlc} \mathrm{level,} \mathrm{BP} \mathrm{profile} \mathrm{and} \mathrm{presence}$ of dipper were also not related to development of microvascular complications. Thus, age at diagnosis, mean HbAlc level from T1DM diagnosis to complication development, and puberty status at diagnosis were significantly predictive of DR development. For microalbuminuria, only mean $\mathrm{HbAlc}$ level was significantly predictive.

\section{Discussion}

T1DM is potentially associated with serious microvascular and macrovascular complications. Although intensive glycemic control reduces the incidence of microvascular and macrovascular complications, many patients with T1DM still develop complications such as microalbuminuria, neuropathy, and retinopathy specific to diabetes. Hyperglycemia predominantly affects the retina, peripheral nerves, and renal glomeruli, none of which can downregulate glucose uptake in the presence of increased levels of extracellular glucose.9) Not only hyperglycemia but also diabetes duration, age, and pubertal stage are critical factors affecting development of microvascular complications. ${ }^{10)}$ Several studies reported that impaired BP regulation and increased BP influence the

Table 4. Predictors for microvascular complications

\begin{tabular}{|c|c|c|c|c|c|c|c|c|}
\hline \multirow{2}{*}{ Variable } & \multicolumn{4}{|c|}{ Diabetic retinopathy } & \multicolumn{4}{|c|}{ Microalbuminuria } \\
\hline & HR (95\% Cl) & $P$-value & Adj. $\mathrm{HR}^{\dagger}(95 \% \mathrm{Cl})$ & Adj. P-value & $\mathrm{HR}(95 \% \mathrm{Cl})$ & $P$-value & Adj. $\mathrm{HR}^{\dagger}(95 \% \mathrm{Cl})$ & Adj. P-value \\
\hline Age at diagnosis (yr) & $1.33(0.98-1.81)$ & 0.070 & & & $1.54(0.93-2.55)$ & 0.096 & & \\
\hline Mean $\mathrm{HbA} 1 \mathrm{c}(\%)^{\ddagger}$ & $4.84(1.97-11.92)$ & $<0.001$ & & & $3.78(1.19-12.03)$ & 0.024 & & \\
\hline Puberty at diagnosis & $8.48(1.10-65.67)$ & 0.041 & & & $524.01(0.00-2.70)$ & 0.490 & & \\
\hline 24-Hour sBP SDS & $1.28(0.69-2.38)$ & 0.430 & $1.92(0.16-23.13)$ & 0.608 & $0.91(0.37-2.25)$ & 0.845 & $0.62(0.12-3.19)$ & 0.570 \\
\hline 24-Hour dBP SDS & $1.13(0.54-2.36)$ & 0.739 & $1.40(0.38-5.14)$ & 0.613 & $1.49(0.60-3.66)$ & 0.389 & $2.36(0.29-18.95)$ & 0.420 \\
\hline 24-Hour MAP SDS & $1.33(0.72-2.45)$ & 0.367 & $0.97(0.35-2.68)$ & 0.960 & $1.3(0.56-3.00)$ & 0.536 & $1.25(0.28-5.59)$ & 0.770 \\
\hline Daytime sBP SDS & $1.12(0.59-2.12)$ & 0.728 & $0.55(0.16-1.90)$ & 0.347 & $0.86(0.33-2.23)$ & 0.759 & $0.75(0.16-3.53)$ & 0.720 \\
\hline Daytime dBP SDS & $0.89(0.43-1.83)$ & 0.751 & $0.89(0.30-2.66)$ & 0.835 & $1.24(0.49-3.13)$ & 0.643 & $1.91(0.32-11.41)$ & 0.478 \\
\hline Daytime MAP SDS & $0.97(0.48-1.95)$ & 0.930 & $0.73(0.26-2.07)$ & 0.555 & $1.07(0.40-2.83)$ & 0.891 & $1.20(0.29-4.99)$ & 0.806 \\
\hline Nighttime sBP SDS & $1.64(0.87-3.09)$ & 0.128 & $1.06(0.33-3.44)$ & 0.917 & $0.88(0.34-2.26)$ & 0.794 & $0.40(0.08-2.14)$ & 0.285 \\
\hline Nighttime dBP SDS & $1.64(0.73-3.67)$ & 0.230 & $3.21(0.51-20.35)$ & 0.216 & $1.41(0.46-4.36)$ & 0.550 & $0.64(0.09-4.46)$ & 0.651 \\
\hline Nighttime MAP SDS & $1.56(0.82-2.97)$ & 0.179 & $1.63(0.48-5.60)$ & 0.437 & $1.08(0.43-2.73)$ & 0.865 & $0.50(0.10-2.67)$ & 0.413 \\
\hline
\end{tabular}

$\mathrm{HR}$, hazard ratio; $\mathrm{Cl}$, confidence interval; HbA1C, glycated hemoglobin A; sBP, systolic blood pressure; SDS, standard deviation score; dBP, diastolic blood pressure; MAP, mean arterial pressure.

${ }^{\dagger}$ Multivariate analysis with adjusting age at diagnosis and average $\mathrm{HbA} 1 \mathrm{c}$ level. ${ }^{\ddagger}$ Average $\mathrm{HbA} 1 \mathrm{c}$ from diagnosis to last follow-up. 
occurrence of microvascular complications in both children and adolescents. ${ }^{4,511,12)}$ The effectiveness of BP evaluation using ABPM has been actively investigated in adults, but there have been relatively few studies in children. Masked hypertension prevalence, a predictor of target-organ damage in children, ${ }^{13,14)}$ is reportedly $9.5 \%$ in youths with T1DM. ${ }^{15)}$ In our study, 38 patients (46.9\%) were identified as having masked hypertension using ABPM. The 2014 American Heart Association statement recommended ABPM implementation in T1DM patients. However, although BP is influenced by age, sex, body size, and ethnicity, particularly in pediatric patients, there have been few ABPM studies in pediatric T1DM patients in Korea. The main findings of this study were identification of risk factors for microvascular complications, incidence of complications, BP profiles determined by ABPM in pediatric T1DM patients in Korea, and the need to measure ABPM in children and adolescents.

$\mathrm{HbA1c}$, age at diagnosis, and puberty status at diagnosis were previously reported to be associated with DR. ${ }^{16)}$ However, in our study, the only modifiable predictor of microvascular complications was high $\mathrm{HbA} 1 \mathrm{c}$ level after adjustment for T1DM duration. In comparisons of the $3 \mathrm{BP}$ groups (dipper, nondipper normotension, nondipper hypertension), DR incidence was significantly higher in the nondipper group than the dipper group, suggesting that circadian BP changes are associated with microvascular complications. However, high BP, altered circadian BP rhythm, sex, and BMI were not predictors of microvascular complications. Although no association between BP profile and microvascular complications was found, there was a significant difference in mean BP between patients with complications and those without complications. These results may be due to the low incidence of microvascular complications or the long duration from ABPM measurement to complication development. Therefore, further evaluation of the relationships of circadian BP alterations and BP profiles with microvascular complications is needed.

In patients with childhood-onset T1DM, the cumulative prevalence of microalbuminuria is approximately $25 \%-30 \%$ at 10 years and $40 \%-60 \%$ at 20 years after T1DM diagnosis. ${ }^{17,18)}$ Prevalence of DR, which causes vision loss, ranged from $50 \%$ to $90 \%$ at 10 and 20-30 years after T1DM diagnosis, respectively, according to a 2017 study. ${ }^{19)}$ A 2019 multicenter study in the United Kingdom reported a DR prevalence of $11 \%$ and a mean diabetes duration of $7.67 \pm 3.72$ years. ${ }^{20)}$ In our study, $7.4 \%$ of patients were diagnosed with DR, and their mean T1DM duration was $14.6 \pm 2.6$ years. Only $3.7 \%$ of patients were diagnosed with microalbuminuria, and their mean diabetes duration was $13.0 \pm 4.4$ years; none were diagnosed with macroalbuminuria. The incidence of microvascular complications should be re-examined for a diabetes duration of 20 or 30 years. The incidence of microvascular complications at 10 years was lower in our study compared with previous studies, ${ }^{17-19)}$ possibly due to the management of blood sugar via insulin multitime therapy and regular outpatient clinical examinations. The incidence and severity of complications at a diabetes duration of 10 years have decreased in recent years for T1DM patients. Updated projections should be used when informing newly diagnosed individuals of their prognosis and for healthcare cost assessments. Blood sugar management via continuous glucose monitoring (CGM) was introduced in Korea approximately 5 years ago, and is now covered by insurance; thus, many patients currently use CGM. ${ }^{21)}$ Therefore, further research is needed on changes in blood glucose management and incidence of microvascular complications after application of stricter blood glucose control using CGM.

There are no reports of BP levels measured by ABPM in T1DM patients in Korea. The BP profiles from our study population are summarized in Table 2. Usually, treatment criteria for high $\mathrm{BP}$ and the definition of hypertension for the general public are $\mathrm{BP}>95$ th percentile. T1DM patients with BP $>90$ th percentile should be treated with angiotensin-converting enzyme inhibitors or other BP-lowering agents. ${ }^{16)}$ Routine 24hour ABPM is recommended for patients with diabetes mellitus to assess BP patterns such as blunted dipping or isolated sleep hypertension. ${ }^{6}$ Alterations in circadian BP rhythm have been frequently documented in hypertension, type 2 diabetes mellitus, chronic kidney disease, and sleep apnea syndrome, and are generally regarded as a harmful condition. ${ }^{22)}$ Kilic and Baydar $^{23}$ suggested that patients with nondipper normotension are at risk of target-organ damage. In this study, no association between BP and occurrence of microvascular complications was identified. However, the link between BP and microvascular complications in T1DM patients is widely known. Therefore, BP monitoring and strict management using ABPM are needed and should be evaluated.

This study had some limitations. First, the size of the patient population was small compared with larger studies of type 2 diabetes. Second, as BP was not measured by ABPM at the time of complication development, the degree of complications caused by changes in BP measured by ABPM is unknown. Third, few patients had complications, therefore, there were limitations in analyzing the characteristics of patients with microvascular complications. Fourth, ABPM SDS values are not accurate because there are no recent data for height and sex of Korean children and adolescents, so we calculated these values based on data from a 2002 paper.

In conclusion, although, several factors that affect occurrence of microvascular complications have been evaluated, blood sugar control is very important over the long term, and further research on circadian $\mathrm{BP}$ alterations is needed. Blood sugar monitoring using CGM, BP monitoring using ABPM, and their impacts on disease progression require additional studies. Also, a large-scale study is needed to determine the value of ABPM SDS for Korean children and adolescents.

\section{Ethical statement}

This study was conducted according to the Declaration of Helsinki, and the protocol was approved by the Ethics Committee of Seoul National University. The need for informed 
consent was waived with approval from the Seoul National University Institutional Review Board (IRB No. H-2007-1961144).

\section{Supplementary material}

Supplementary Tables 1,2, and Fig. 1 can be found via https:// doi.org/10.6065/apem.2142084.042.

\section{Notes}

Conflicts of interest: No potential conflict of interest relevant to this article was reported.

Funding: This study received no specific grant from any funding agency in the public, commercial, or not-for-profit sectors.

\section{Author contribution}

Conceptualization: CHS; Data curation: JL, YAL, CHS; Formal analysis: YJL, YAL, CHS; Project administration: JL, CHS; Writing - original draft: JL; Writing - review \& editing: J Lee, YJ Lee, YA Lee, CHS

\section{ORCID}

Jeong-Seon Lee: 0000-0001-8278-458X

Yun Jeong Lee: 0000-0003-2847-2643

Young Ah Lee: 0000-0001-9179-1247

Choong Ho Shin: 0000-0002-9813-1134

\section{References}

1. Chillaron JJ, Flores Le-Roux JA, Benaiges D, Pedro-Botet J. Type 1 diabetes, metabolic syndrome and cardiovascular risk. Metabolism 2014;63:181-7.

2. Marcovecchio ML, Dalton RN, Schwarze CP, Prevost AT, Neil HA, Acerini CL, et al. Ambulatory blood pressure measurements are related to albumin excretion and are predictive for risk of microalbuminuria in young people with type 1 diabetes. Diabetologia 2009;52:1173-81.

3. Flynn JT, Kaelber DC, Baker-Smith CM, Blowey D, Carroll AE, Daniels SR, et al. Clinical practice guideline for screening and management of high blood pressure in children and adolescents. Pediatrics 2017;140:e20171904.

4. Dost A, Bechtold-Dalla Pozza S, Bollow E, Kovacic R, Vogel $\mathrm{P}$, Feldhahn L, et al. Blood pressure regulation determined by ambulatory blood pressure profiles in children and adolescents with type 1 diabetes mellitus: Impact on diabetic complications. Pediatr Diabetes 2017;18:874-82.

5. Lee SH, Kim JH, Kang MJ, Lee YA, Won Yang S, Shin $\mathrm{CH}$. Implications of nocturnal hypertension in children and adolescents with type 1 diabetes. Diabetes Care 2011;34:2180-5.

6. Flynn JT, Daniels SR, Hayman LL, Maahs DM, McCrindle BW, Mitsnefes M, et al. Update: ambulatory blood pressure monitoring in children and adolescents: a scientific statement from the American Heart Association.
Hypertension 2014;63:1116-35.

7. Kim JH, Yun S, Hwang SS, Shim JO, Chae HW, Lee YJ, et al. The 2017 Korean National Growth Charts for children and adolescents: development, improvement, and prospects. Korean J Pediatr 2018;61:135-49.

8. Wuhl E, Witte K, Soergel M, Mehls O, Schaefer F, German Working Group on Pediatric H. Distribution of 24-h ambulatory blood pressure in children: normalized reference values and role of body dimensions. J Hypertens 2002;20:1995-2007.

9. Katsarou A, Gudbjornsdottir S, Rawshani A, Dabelea D, Bonifacio E, Anderson BJ, et al. Type 1 diabetes mellitus. Nat Rev Dis Primers 2017;3:17016.

10. Brink SJ. Complications of pediatric and adolescent type 1 diabetes mellitus. Curr Diab Rep 2001;1:47-55.

11. Ayer JG, Harmer JA, Nakhla S, Xuan W, Ng MK, Raitakari OT, et al. HDL-cholesterol, blood pressure, and asymmetric dimethylarginine are significantly associated with arterial wall thickness in children. Arterioscler Thromb Vasc Biol 2009;29:943-9.

12. Urbina EM, Kimball TR, McCoy CE, Khoury PR, Daniels SR, Dolan LM. Youth with obesity and obesity-related type 2 diabetes mellitus demonstrate abnormalities in carotid structure and function. Circulation 2009;119:2913-9.

13. Lurbe E, Torro I, Alvarez V, Nawrot T, Paya R, Redon J, et al. Prevalence, persistence, and clinical significance of masked hypertension in youth. Hypertension 2005;45:493-8.

14. Stabouli S, Kotsis V, Toumanidis S, Papamichael C, Constantopoulos A, Zakopoulos N. White-coat and masked hypertension in children: association with targetorgan damage. Pediatr Nephrol 2005;20:1151-5.

15. Sulakova T, Janda J, Cerna J, Janstova V, Sulakova A, Slany J, et al. Arterial HTN in children with T1DM--frequent and not easy to diagnose. Pediatr Diabetes 2009;10:441-8.

16. Donaghue KC, Marcovecchio ML, Wadwa RP, Chew EY, Wong TY, Calliari LE, et al. ISPAD Clinical Practice Consensus Guidelines 2018: Microvascular and macrovascular complications in children and adolescents. Pediatr Diabetes 2018;19 Suppl 27:262-74.

17. Amin R, Widmer B, Prevost AT, Schwarze P, Cooper J, Edge J, et al. Risk of microalbuminuria and progression to macroalbuminuria in a cohort with childhood onset type 1 diabetes: prospective observational study. BMJ 2008;336:697-701.

18. Kwon AR, Lee S, Chae HW, Kim DH, Kim HS. Frequencies and related factors for microvascular complications in patients with type 1 diabetes. Ann Pediatr Endocrinol Metab 2012;17:16-26.

19. Khalil H. Diabetes microvascular complications-A clinical update. Diabetes Metab Syndr 2017;11 Suppl 1:S133-9.

20. Ng SM, Ayoola OO, McGuigan MP, Chandrasekaran S. A multicentre study evaluating the risk and prevalence of diabetic retinopathy in children and young people with type 1 diabetes mellitus. Diabetes Metab Syndr 2019;13:744-6. 
21. Kim JH. Current status of continuous glucose monitoring among Korean children and adolescents with type 1 diabetes mellitus. Ann Pediatr Endocrinol Metab 2020;25:145-51.

22. Cuspidi C, Sala C, Tadic M, Gherbesi E, De Giorgi A, Grassi $\mathrm{G}$, et al. Clinical and prognostic significance of a reverse dipping pattern on ambulatory monitoring: an updated review. J Clin Hypertens (Greenwich) 2017;19:713-21.

23. Kilic A, Baydar O. The relationship between diurnal blood pressure abnormalities and target organ damage in normotensive subjects. Which is more important? Increased blood pressure levels or circadian blood pressure abnormalities. Clin Exp Hypertens 2020;42:244-9. 